\title{
DEMOCRACIA E CAPITAL SOCIAL NA AMÉRICA LATINA: UMAANÁLISE COMPARATIVA
}

\author{
Everton Santos
}

\author{
Marcello Baquero
}

\begin{abstract}
RESUMO
Este artigo tem como objetivo principal identificar as possíveis condições societais que favorecem a democracia na América Latina, articulando o conceito de democracia com o conceito de capital social na tradição de Putnam. Nossa hipótese de trabalho é que há uma associação significativa entre capital social e democracia e de que a existência de estoques de capital social, em uma determinada sociedade, influencia positivamente a crença no regime democrático e em suas instituições. A hipótese é testada utilizando os dados de três capitais sul americanas: Porto Alegre (Brasil), Montevidéu (Uruguai) e Santiago (Chile), a partir de três surveys aplicados nesses países.
\end{abstract}

PALAVRAS-CHAVE: democracia; capital social; América Latina.

\section{INTRODUÇÃO}

Na década de 1980, um conjunto expressivo de países da América Latina sofreu mudanças significativas em seus regimes políticos, transitando de regimes "não-democráticos" para formas "democráticas" de governo, caracterizando, assim, um importante fenômeno de mudança política. Várias perspectivas teóricas foram utilizadas para analisar a dinâmica deste processo de construção democrática. Por exemplo, uma vertente enfatizava a modernização da sociedade, enquanto que outra centrava-se na escolha dos atores. O ponto central, no entanto, da maioria das perspectivas teóricas sobre este tema era procurar argumentos que dessem conta de explicar sua emergência e sua estabilidade, como regime político.

Nas últimas duas décadas, influenciadas pelas deficiências da democracia representativa, no que refere-se à resolução de problemas econômicos, políticos e sociais, bem como à persistência de uma situação em que a credibilidade e legitimidade da democracia formal são constantemente questionadas, tornou-se necessário procurar explicações teóricas alternativas de um cenário em que a democracia poliárquica convive pacificamente com problemas de crescente pobreza e exclusão social e, sobretudo, com a instabilidade societária. Nestas circunstâncias, surge o conceito de capital social como conceito e abordagem diferente das perspectivas mais tradicionais, que buscam não só explicar os déficits democráticos, mas propor mecanismos tangíveis de geração de estabilidade política, baseados na confiança recíproca, na solidariedade e na participação comunitária via associações informais.

Nessa direção, o presente artigo examina três cidades na América Latina: Porto Alegre (Brasil), Montevideu (Uruguai) e Santiago do Chile (Chile), objetivando analisar as condições societais que favorecem, ou não, a democracia nesta região, articulando conceito de democracia com o conceito de capital social na tradição de Putnam (2000).

Nossa hipótese de trabalho postula a existência de uma associação entre capital social e democracia. Subjacente a esta hipótese, está a premissa que sugere que a presença de estoques de capital social, conceituada em termos de confiança institucional e interpessoal, em uma determinada sociedade, influencia positivamente a crença no regime democrático e em suas instituições.

Para testar a hipótese deste trabalho, o artigo está dividido em três tópicos. No primeiro, “As possibilidades da democracia”, discute-se, numa dimensão teórico-normativa, os benefícios advindos de uma democracia, como regime político. Nesta seção, a democracia é examinada a partir da vertente que defende ser a democracia fruto da modernização da sociedade. Numa linha teórica contrária à perspectiva da modernização, 
examina-se aquela abordagem que centra sua atenção na escolha dos atores políticos, segundo o qual a democracia seria fruto da escolha racional de lideranças políticas que tornam a democracia possível. Argumentaremos que as formulações oriundas desta vertente teórica (atores políticos) não concretizaram-se, pelo contrário, produziram uma frustração teórica, à medida que, de uma maneira geral, a democracia social e a prosperidade social, por eles defendidas, não efetivaram-se.

Presentemente, constata-se uma convergência de pensamento a respeito de que a democracia depende, não somente da dimensão econômica, mas também da constituição de uma base de apoio normativo, ou seja, normas e crenças que valorizem os princípios democráticos também são essenciais para o processo de amadurecimento democrático. O fortalecimento da democracia, tanto na sua dimensão formal quanto no aspecto substantivo, portanto, age integradamente.

No segundo tópico, "Um modelo alternativo para compreender-se a democracia: capital social”, é proposto um modelo de democracia mais abrangente, que vai além de explicações de caráter poliárquico, como a escolha das lideranças políticas e as reformulações das instituições e das leis. Estes aspectos são essenciais numa democracia e têm sido amplamente examinados pela vertente institucionalista, a qual demonstra, com razão, que nenhum sistema político pode sobreviver sem instituições e regras de convivência democrática (tese minimalista). Não é o propósito deste artigo questionar a importância de procedimentos democráticos formais, obviamente o são, seria ingênuo pensar o contrário. Igualmente, não queremos tratar aspectos formais e informais da democracia como uma dicotomia, pois isto significaria sair de uma normatividade teórica para cair em outra. $\mathrm{O}$ que o texto discute é que, a menos que leve-se em conta a dimensão social da democracia (saúde, moradia, educação, transporte e segurança pública), dificilmente países com sua base material não resolvida poderão alcançar um sistema democrático e participativo com eqüidade social (tese maximalista). Partimos do princípio de que a democracia não pode prescindir, sob pena de comprometer sua estabilidade, credibilidade e legitimidade de crenças, normas e princípios que valorizem as instituições políticas e os gestores públicos. São estes elementos que ajudam a formatar uma cultura política na qual institucionaliza-se uma base de apoio normativo ao regime democrático.
O artigo conclui abordando a questão da "Democracia e capital social”, utilizando dados empíricos, fruto de pesquisa probabilística comparativa em três capitais latino-americanas: Porto Alegre (Brasil), Montevidéu (Uruguai) e Santiago do Chile (Chile). Nesta pesquisa quantitativa, de estilo survey, foram aplicados cerca de 500 questionários em cada cidade, entre maio e julho de 2005, observando um intervalo de confiança de $95 \%$ e um erro amostral de $4 \%$. Estes dados possibilitam encontrar resposta às perguntas: Em que medida, a confiança interpessoal pode estar associada à crença na democracia? Em que medida, as três capitais, em perspectiva comparada, apresentam uma regularidade para além das idiossincrasias destes países? Quais são as particularidades de cada país? Como capital social e democracia estão associados em cada caso examinado?

\section{AS POSSIBILIDADES DA DEMOCRACIA}

Vive-se hoje, na América Latina, de forma geral, neste início de século XXI, um regime do tipo democrático representativo com características formais (DAHL, 1997). Isto significa que há eleições regulares, abertas e competitivas. Os líderes são escolhidos por meio destes mecanismos eleitorais, uma vez eleitos, governam por intermédio de instituições por tempo determinado. A sociedade tem o direito à organização, e a contestação política é permitida. Em outras palavras: a poliarquia está instituída.

Nos países analisados, Brasil, Uruguai e Chile, este regime foi resultado de uma construção histórica e política recente, pois, desde os golpes militares, nas décadas de 1960 e 1970, até meados da década de 1980, vivia-se sob um regime autoritário que produziu sociedades reprimidas e fortemente censuradas pelo Estado.

Este legado histórico e cultural incorporou-se a uma nova situação política e institucional (legal) diferente destes anos pretéritos. De fato, o Brasil e um conjunto expressivo de países da América Latina, que sofreram mudanças significativas nas últimas décadas, transitaram de regimes "não-democráticos" para formas "democráticas de governo”. Uma verdadeira “onda democrática”, para usar a expressão de Huntington (1994), atingiu diferentes países no continente americano. Todavia, este fenômeno trouxe uma tarefa bastante complexa para a comunidade acadêmica, pois tornou-se necessário explicá-lo à luz da prevalência 
simultânea de graves problemas sociais.

As tentativas de explicar a convivência entre regimes democráticos e Estados oligárquicos gerou divergências teóricas entre cientistas políticos, divergências que, na nossa opinião, têm sido pouco úteis na tarefa maior de encontrar mecanismos de amadurecimento democrático. Como ilustração, podemos encontrar dissensos entre aqueles que explicam a democracia pelas estruturas, isto é, os teóricos da modernização, para quem a democracia é o resultado direto do desenvolvimento econômico, e aqueles que apostam na qualidade dos atores (das lideranças políticas) que, a partir de suas escolhas racionais, tornam a democracia possível.

\section{II.1. Os teóricos da modernização}

As teorias da modernização, afloradas após a II Guerra Mundial, entendiam que a modernização levaria, inevitavelmente, à institucionalização da democracia, ou seja, sinalizavam para o crescimento econômico, para a urbanização, para os índices crescentes de melhoria no nível educacional das populações e para a qualidade da saúde, somados a uma visão de futuro com confiança, que incidiriam em um processo virtuoso de construção democrática, pois tais sociedades demandariam cidadãos autônomos e organizados. Neste sentido, a modernização aparecia como pré-condição necessária para a emergência e a estabilidade de um governo democrático (NUN, 1994). Era uma visão evolucionista da sociedade que contrapunha o tradicional ao moderno. Acreditava-se que a modernização era a variável independente e a democracia, a variável dependente. Este raciocínio respaldava o planejamento econômico e a implementação de políticas públicas, aparentemente direcionadas pelos gestores públicos para promover condições objetivas para a democracia, dando-se ênfase aos aspectos econômicos em detrimento dos políticos e sociais.

Como a história mostra, porém, as teorias da modernização que influenciaram o pensamento da intelectualidade latino-americana falharam, pois o processo de modernização capitaneado pelos Estados nesta região, nos anos 1950 e 1960, por exemplo, que "prometiam a paz e a prosperidade”, desembocaram em regimes autoritários, na segunda metade do século XX.

A situação pouco modificou-se com o advento das novas democracias na década de 1980 . No caso brasileiro, pontualmente, o péssimo desempenho da economia brasileira na chamada "década perdida” não provocou mudanças significativas no campo social, revelando a insuficiência de fatores exclusivamente econômicos no desenvolvimento social de um país. Neste sentido, as limitações de explicações meramente técnicas mostraram que, do ponto de vista da variável estritamente "econômica", caso fosse absolutamente indispensável para a democracia, o Brasil teria retornado ao regime autoritário (MAINWARING, 1992). A prevalência de um cenário instável político, concomitantemente ao crescimento da pobreza e da exclusão social, apontou para a impotência da teoria da modernização em explicar não só as possibilidades da democracia, mas, sobretudo, os processos de transição democrática, à medida que perdera seu poder de explicação. Se a modernização, ou seja, a urbanização, a educação e o crescimento econômico não explicam a democracia, o que poderia explicá-los melhor?

\section{II.2. A aposta nos atores políticos}

Uma abordagem que se contrapõe à perspectiva da modernização e que centra-se como unidade de análise nos atores políticos, está nos escritos, principalmente, de O’Donnell e Schmitter (1986; 1988). Se a teoria da modernização mostrava-se limitada na sua capacidade explicativa, por enfatizar apenas os aspectos estruturais (econômicos e sociais) em prejuízo dos aspectos políticos, a perspectiva apresentada por O’Donnell e Schmitter coloca no âmago de sua análise os atores (as lideranças políticas) e suas ações racionais em prejuízo da dimensão estrutural (modernização). O raciocínio analítico desta linha de pensamento está situado na idéia de que, mesmo levando em conta as condições econômicas da transição à democracia que estavam na base do processo histórico brasileiro, o papel das lideranças políticas era crucial para assegurar o sucesso do resultado final dos processos de mudança (a passagem do autoritarismo para a democracia), pois seriam elas, por meio de sua capacidades, as mais habilitadas a aproveitarem ao máximo as oportunidades que surgiram no contexto político da época, para tomarem suas decisões e colocarem o Brasil no caminho da democracia (MOISÉS, 1995).

Na perspectiva teórica dos atores, as lideranças políticas envolvidas escolhem o melhor caminho para construir a democracia. No entanto, o 
caminho escolhido não tem produzido os resultados esperados, especialmente no sentido de produzir um sistema político mais justo e equitativo socialmente. No Brasil, o enfoque predominante tem sido o institucional, ou seja, escolheu-se chegar à democracia, seguindo o calendário eleitoral, parlamentar, o chamado "cálculo da descompressão” (LAMOUNIER, 1987).

Tal opção não significou, entretanto, a negação de fatores estruturais macroeconômicos relativos à sistemática mundial ou mesmo nacional. No entanto, tornou-se fundamental levar em conta a qualidade das lideranças. Nestas circunstâncias, a democracia brasileira tem sido atribuída ou à modernização ou à escolha dos seus representantes políticos. Todavia, da mesma forma que a teoria de modernização, esta segunda vertente acabou falhando não só na sua capacidade de prognosticar o futuro do país, mas, sobretudo, na constatação de que a qualidade dos atores políticos escolhidos, ou seja, a classe política, tem contribuído decisivamente para a instalação de um questionamento permanente, por parte dos cidadãos, sobre a credibilidade e a legitimidade dos procedimentos democráticos e, em alguns casos, sobre a própria essência da democracia. Não por acaso, dados do latinobarometro em 2004 revelaram que mais de $50 \%$ dos latino-americanos aceitariam um regime autoritário, desde que resolvesse os problemas dos países. Estas predisposições estão ancoradas numa decepção/frustração dos eleitores com as promessas eleitorais não cumpridas pelos governos eleitos

\section{II.3. As promessas não cumpridas}

De maneira geral, a democracia, na perspectiva da modernização ou da escolha dos atores pode ser caracterizada como uma "transição", ou seja, um processo complexo, porém, seqüencial que possibilita ir de um regime autoritário para a democracia. Todavia, a série de suposições deste esquema analítico foi quebrada, segundo Carothers (2002). Primeiro: porque os países que estavam em "transição” praticamente não democratizaram-se; segundo: os estágios presumidos não foram obedecidos como no esquema teórico; terceiro: a regularidade das eleições não levou à responsabilidade política dos governantes; quarto: a democratização não mostrou-se uma tarefa determinantemente dependente de elites políticas, mas também de fatores estruturais; quinto: a construção do Estado tem sido um assunto muito mais complexo do que supu- nham, inicialmente, os teóricos.

Os fatores limitantes da construção democrática, neste sentido, não podem ser atribuídos apenas às deficiências das elites políticas ao desenharem uma democracia orientada para o social, mas também dependem de aspectos estruturais. Desta maneira, estudos desenvolvidos sobre esta temática, nos últimos anos, têm apontado para uma retomada da teoria da modernização, porém, a partir de ângulo diferente.

\section{II.4. A retomada das análises estruturais}

No que diz respeito à dimensão estrutural, Huntington (1994) retomou, a partir de aspectos diferentes, as análises que enfatizavam a dimensão econômica. Para o autor, os processos de democratização que começaram na década de 1970, levando cerca de 30 países "não-democráticos" a "regimes democráticos”, vão além de explicações unilineares. Nesta direção, a centralidade de sua análise reside na busca de uma correlação entre riqueza e democratização, mas não ao modelo das “análises ortodoxas", que afirmavam ser os países ricos democráticos e que, portanto, a riqueza produziria inevitável e instantaneamente uma melhor qualidade da democracia.

Embora saliente que os fatores econômicos não sejam determinantes para promover a democratização, segundo Huntington (1994), produzem um impacto significativo. As análises realizadas por ele, desta forma, constatam uma correlação positiva entre riqueza e democratização. Porém, enfatizam que não somente a riqueza, mas a sua permanência, em longo prazo, podem promover um ambiente propício à democratização. Não se pode negar que um desenvolvimento econômico que crie condições para o avanço social possa criar um lastro favorável para a democratização em longo prazo.

O vaivém das perspectivas tradicionais de democracia e sua incapacidade em proporcionar explicações plausíveis para a crise contemporânea na América Latina abriram o caminho para refletir sobre o papel das formas alternativas de envolvimento político, à margem da institucionalidade vigente, implicadas no avanço democrático desta região.

III. UM MODELO ALTERNATIVO PARA COMPREENDER-SEADEMOCRACIA: CAPITAL SOCIAL

Weber já sublinhara que, nas Ciências Sociais, 
corre-se o risco do erro ao apostarmos na monocasualidade para a explicação de um problema sociológico. Há diferentes fatores que podem contribuir para a ocorrência de determinado fenômeno. Desta maneira, seguindo os estudos contemporâneos sobre a democracia, podemos flexibilizar tanto as "apostas estruturais" como as apostas nos “atores”, problematizando a questão da democracia a partir de uma base que toma como elemento constitutivo o papel protagônico dos cidadãos, organizados em entidades informais, locais e comunitárias. Ou, como propõe José Álvaro Moisés (1995), um modelo balanceado, mais abrangente, que supere as visões unilaterais (estrutura e atores) as quais ele chama de “maximalismo" e "minimalismo".

A perspectiva "minimalista” parte do pressuposto de que a democracia é possível sob condições mínimas, ou seja, não são precisos pré-requisitos econômicos, sociais ou mesmo culturais para que estabeleça-se, pois ela dependeria basicamente da escolha dos atores envolvidos, dos seus pactos, de certas regras e da aposta nos atores políticos. Já na perspectiva “maximalista”, parte-se do pressuposto de que a democracia não é possível sob condições mínimas, pois condições econômicas, sociais e culturais exercem também um importante condicionamento sobre ela. Não haveria sustentação da democracia sem estes lastros, sem um apoio normativo.

Nesta concepção deve-se levar em conta tanto a liberdade de escolha dos atores políticos, no curso das transformações proporcionadas pelos processos de mudança política, como os condicionantes impostos a estas situações, dados pela presença ou pela ausência de condições sociais, econômicas, políticas e culturais. Então, enquanto as mudanças econômicas e sociais induzidas pelos processos de modernização econômica ampliam as bases, a partir das quais estas iniciativas podem ser tomadas, cabe ao esforço das lideranças políticas gerar as condições de sucesso da criação da democracia (idem).

Atores que fazem suas escolhas sob condições favoráveis à democracia têm grande possibilidade de lograr êxito, mas Moisés (idem) vai além dessa formulação. Para ele, só se efetivará, dotando-se os governos de mecanismos que dêemlhes autoridade para gerar e implementar políticas e, principalmente, criar instituições que sejam respaldadas por atitudes e comportamentos demo- cráticos das massas. É desta forma que seu "modelo balanceado" (entre os maximalistas e minimalistas) chama a atenção para a dimensão da cultura política como um fator indispensável para a construção de regimes democráticos. A variável "cultura política” é introduzida no debate, entendida aqui como um conjunto de atitudes e comportamentos que os cidadãos têm em relação ao sistema político e que são indispensáveis para a sustentação das instituições da democracia (ALMOND \& VERBA, 1989).

De fato, não é possível afirmar que parcelas significativas de cidadãos que rejeitem ou sejam indiferentes aos valores democráticos (que não possuem uma cultura de afirmação dos valores democráticos, por exemplo) não sejam uma variável comprometedora da estabilidade política. $\mathrm{Na}$ verdade, estas parcelas de eleitores podem ter papel decisivo na manutenção de um sistema intolerante e instável, não permitindo construir regimes democráticos na América Latina. Assim, ao contrário das democracias ocidentais, em que já existe um regime democrático construído, este elemento (cultura política) talvez não seja tão importante, mas em sociedades materialmente não resolvidas, este aspecto pode ser crucial para a estabilidade política e societária (BAQUERO, 1999).

Não se nega que, no Brasil, nos últimos anos, tivemos avanços significativos em relação à democracia, sobretudo, na dimensão formal, e que, mesmo não havendo um apoio normativo ao regime democrático no país, as eleições ocorrem regularmente, as instituições de certa forma funcionam e nada no horizonte aponta para um retrocesso ao autoritarismo. De fato, houve uma modernização das instituições no país e das suas leis (de uma maneira geral). Todavia, não se pode concluir que a democracia esteja consolidada e funcionando perfeitamente, principalmente se considerada a dimensão social.

Para além da dimensão legal e institucional, é preciso uma certa mudança na cultura política da sociedade para viabilizarmos o melhor funcionamento da democracia, destas leis. Baquero (2005) usa o conceito de democracia inercial para referir-se à democracia brasileira. Neste tipo de democracia, há uma modernização das instituições políticas, uma evolução das leis, das regras, no sentido poliárquico. Contudo, pouco ou nada evolui na dimensão social, ou seja, é uma democracia inercial que apresenta as seguintes característi- 
cas: a) políticas econômicas que não favorecem as massas excluídas e que mantêm o desemprego inalterado e estagnado; b) uma cultura híbrida (misturada) que institucionaliza um comportamento de resignação e hostilidade com a política. Esta cultura política de resignação e hostilidade traduzse em uma cultura de desconfiança generalizada em relação à política, assim como nas relações interpessoais na base da sociedade. O problema deste tipo de configuração cultural é que ele impede o funcionamento da democracia.

O estudo de Baquero segue a linha sobre cultura política que tem-se renovado, precisamente, pelas limitações explicativas das abordagens tradicionais. Nesta direção, o renovado interesse sobre a cultura política retoma o ponto de onde os primeiros estudos sobre este tema experimentaram um declínio, especificamente, os trabalhos de Almond e Verba (1989) e de Inglehart (1978). Numa vertente culturalista, nas duas últimas décadas, institucionaliza-se como categoria analítica na Ciência Política o estudo do capital social como elemento-chave, complementar e, às vezes, como substituto de procedimentos formais, para o funcionamento adequado ou não da democra$\mathrm{cia}^{1}$. Isso não significa que procedimentos formais sejam considerados dispensáveis, pelo contrário, a teoria de capital social busca, em última análise, produzir melhores instituições a partir de experiências informais do cidadão. $\mathrm{O}$ argumento nuclear da teoria de capital social é que, quanto mais "capital social” tem uma sociedade, maior a possibilidade do fortalecimento da democracia na sua dimensão formal e social. Ao contrário, pouco capital social produz sociedades fragmentadas, individualistas e desiguais.

Existe uma vasta literatura sobre diversos aspectos de capital social. Para os objetivos deste artigo, sublinhamos aqueles trabalhos mais significativos para o espectro da América Latina. Entre as principais obras, identificam-se os trabalhos de Bourdieu (1980), Coleman (1988), Putnam (2000) e Fukuyama (1996). Autores estes que têm

1 O funcionamento adequado da democracia, aqui, não é só a capacidade que o regime democrático tem para resolver conflitos políticos, acomodar os interesses das elites, processar o dissenso, porém, sua capacidade em ser eficiente e sensível às demandas da população (PUTNAM, 2000). Em outras palavras: em resolver os problemas da saúde, da educação, da segurança, do emprego, do campo etc. contribuído para o debate epistemológico em torno do conceito de capital social.

Bourdieu (1980), por exemplo, compreende o capital social como uma propriedade do agente, como relações sociais que permitem aos indivíduos ou grupos obterem recursos ou reconhecimento. Já Coleman (1988), contrariamente, vê o capital social não como uma característica do indivíduo, mas num sentido funcional, como um conjunto de elementos numa dada estrutura social que possibilita aos atores satisfazarem seus objetivos. Estes elementos são basicamente as obrigações, os canais de informação e as normas e sanções. Muito embora ambos autores não percam a dimensão da tensão epistêmica entre indivíduo e sociedade no que diz respeito aos dilemas da ação coletiva, poderíamos dizer, forçando a análise, de que Coleman (1988) inclina-se com seu conceito mais para a sociedade e Bourdieu (1980) mais para o indivíduo, ou para usar sua terminologia, para o "agente".

Dentro da hipótese formulada neste trabalho, utilizamos a dimensão teórica de capital social proposta por Robert Putnam (2000) e Fukuyama (1996), que trabalham com a idéia de capital social como um bem comunitário. Para Putnam (2000), capital social são práticas sociais, normas e relações de confiança que existem entre cidadãos numa determinada sociedade, bem como, sistemas de participação e associação que estimulam a cooperação. Deduz-se dessa conceituação que quanto maior for a capacidade dos cidadãos confiarem uns nos outros, para além de seus familiares, assim como quanto maior e mais rica for o número de possibilidades associativas numa sociedade, maior será o volume de capital social. Assim, a confiança é a expectativa que nasce no meio de uma comunidade de comportamento estável e cooperativo, baseado em normas compartilhadas por estes mesmos membros (FUKUYAMA, 1996). A questão central para Putnam (2000) é que a confiança, a cooperação e os espaços de participação social entre o Estado e a sociedade são elementos positivos e essenciais para o bom funcionamento das

2 Não somente para as instituições democráticas, mas também econômicas. Fukuyama (1996) demonstrou que a existência de capital social numa dada sociedade é fator explicativo do tamanho da estrutura industrial ali existente, bem como do desempenho econômico conseqüentemente. 
democracias $^{2}$. Putnam (2000), já havia apontado em seu trabalho, "Comunidade e Democracia”, que os governos do norte da Itália haviam tido um desempenho institucional superior aos governos do sul, cujo volume de capital social era menor em comparação com o norte italiano. Em outras palavras, o autor demonstrou como a comunidade cívica, as relações de confiança são importantes variáveis na explicação do desempenho das instituições democráticas.

São estas variáveis que possibilitarão testar a associação entre capital social e as instituições da democracia nas três capitais latino-americanas: Porto Alegre, Montevidéu e Santiago do Chile, enfatizando, preferencialmente, a dimensão da confiança interpessoal e a crença nas instituições democráticas.

\section{III.1. Democracia e capital social}

O nível de confiança inerente numa sociedade é considerado essencial para o fortalecimento democrático de um país. Da perspectiva do capital social, a confiança recíproca é vista como um dos seus catalisadores. Já existe consenso de que, sem confiança, a democracia é instável e funciona precariamente. Começamos nossa análise empírica indagando aos entrevistados os níveis de confiança interpessoal.

Numa perspectiva de comparação espacial, a Tabela 1 aponta ser a população de Montevidéu aquela com o maior percentual de confiança interpessoal (47,9\%), seguido pela população de Porto Alegre (32,9\%) e, em último lugar, a população de Santiago do Chile (23,2\%). As diferenças, percentualmente, são significativas, sugerindo que, na capital uruguaia, o estoque de capital social ajuda no processo de manutenção da estabilidade política, enquanto que em Porto Alegre e Santiago do Chile mais de três quartos da população não mostram predisposições a confiar nos outros.

TABELA 1 - NÍVEL DE CONFIANÇA INTERPESSOAL (BRASIL, URUGUAI E CHILE)

\begin{tabular}{|l|c|c|c|}
\hline & $\begin{array}{c}\text { PORTO } \\
\text { ALEGRE }\end{array}$ & MONTEVIDÉU & SANTIAGO DO CHILE \\
\hline Pode-se confiar nas pessoas & 32,9 & 47,9 & 23,2 \\
Nẵo se pode confiar nas pessoas & 67,1 & 47,5 & 74,8 \\
Total de entrevistados & 490 & 497 & 496 \\
\hline
\end{tabular}

FONTE: NIEM-NUPESAL (2005).

NOTA: As percentagens podem não somar 100\% em virtude de termos excluído as categorias "não sabe" e "não respondeu", com menos de 5 casos.

As diferenças, na nossa opinião, podem ser atribuídas a uma longa tradição democrática no Uruguai. A desconfiança interpessoal também pode ajudar a compreender o grau de satisfação das pessoas com a democracia. Os dados da Tabela 2 reproduzem o padrão anteriormente observado em relação à confiança interpessoal. São os chilenos os que declararam-se mais insatisfeitos com a democracia, com 38\%, seguidos pelos portoalegrenses, com $35,2 \%$, e os uruguaios, com a menor insatisfação, perfazendo $12,8 \%$. Se um dos pilares do amadurecimento democrático está nas orientações dos cidadãos em relação à democracia, então, a predisposição dos entrevistados em relação à democracia é alentadora, a despeito das oscilações de Montevidéu com as outras capitais.

TABELA 2 - SATISFAÇÃO COM O FUNCIONAMENTO DA DEMOCRACIA(BRASIL, URUGUAI E CHILE)

\begin{tabular}{|l|c|c|c|}
\hline & PORTO ALEGRE & MONTEVDÉU & SANTIAGO DO CHILE \\
\hline Satisfeito & 18,6 & 50,4 & 19,2 \\
Pouco satisfeito & 45,1 & 34,2 & 39,0 \\
Insatisfeito & 35,2 & 12,8 & 38,0 \\
Total de entrevistados & 500 & 500 & 490 \\
\hline
\end{tabular}

FONTE: NIEM-NUPESAL (2005). 
Mostrar, porém, um certo grau de satisfação com a democracia não é sinônimo de confiança nas instituições do sistema democrático. As predisposições são de natureza simbólica e, portanto, evocam respostas de natureza subjetiva. Neste sentido, é relevante avaliar o grau de confiança dos cidadãos nas instituições da democracia representativa. Os dados desta análise estão na Tabela 3.

TABELA 3 - CONFIANÇA NO CONGRESSO NACIONAL (BRASIL, URUGUAI E CHILE)

\begin{tabular}{|lcccc|}
\hline & PORTO ALEG RE & MONTEVIDÉU & SANTIAGO DO CHILE \\
\hline Confia muito & 6,3 & 26,0 & 4,2 \\
Confia pouco & 50,8 & 49,0 & 54,2 \\
Nẵo confia & 39,9 & 21,8 & 40,0 \\
NS & 3,0 & 3,2 & 1,6 \\
Total de entrevistados & 500 & 500 & 500 \\
\hline
\end{tabular}

FONTE: NIEM-NUPESAL (2005).

Em relação ao Congresso Nacional, 40\% dos chilenos disseram não confiar nesta instituição, $39,9 \%$ dos brasileiros e $21,8 \%$ dos uruguaios.

Quanto ao governo federal, conforme Tabela 4, os brasileiros aparecem com $30,8 \%$; os chile- nos, com 28,9\%; os uruguaios, com 17,4\%. Mesmo estando os brasileiros ligeiramente à frente dos chilenos, os uruguaios sempre apresentam percentuais mais expressivos na direção da confiança nestas instituições, quer seja do governo federal ou mesmo do Congresso Nacional.

TABELA 4 - CONFIANÇA NO GOVERNO FEDERAL (PRESIDENTE E MINISTROS) (BRASIL, URUGUAI E CHILE)

\begin{tabular}{|l|c|c|c|}
\hline & PORTO ALEGRE & MONTEVIDÉU & SANTIAG O DO CHILE \\
\hline Confia muito & 10,3 & 45,1 & 16,4 \\
Confia pouco & 57,6 & 35,5 & 54,5 \\
Nã̃o confia & 30,8 & 17,4 & 28,9 \\
Total de entrevistados & 500 & 500 & 499 \\
\hline
\end{tabular}

FONTE: NIEM-NUPESAL (2005)

O que cabe ressaltar dos dados das tabelas sobre confiança institucional é a elevada percentagem de cidadãos que confiam pouco ou não confiam nas instituições convencionais de mediação política.

Neste cenário de desconfiança generalizada, como as pessoas posicionam-se em relação a quem é responsável pela resolução dos problemas do país? Essa indagação torna-se pertinente para avaliar a existência de relações terciárias (identificação direta entre mandatários e população) em detrimento de relações secundárias de mediação política (partidos e Congresso), propiciando, desta maneira, a prevalência de traços tradicionais da prática política, entre as quais o clientelismo, o personalismo e o patrimonialismo. A Tabela 5 contém as respostas a este questionamento.

TABELA 5 - RESOLUÇÃO DOS PROBLEMAS DO BRASIL

\begin{tabular}{|lcccc|}
\hline & PORTO ALEGRE & MONTEVIDÉU & SANTIAGO DO CHILE \\
\hline Um líder & 34,3 & 28,2 & 30,4 \\
Participaçã̃o da populaçã̃o & 65,7 & 69,4 & 65,6 \\
Total de entrevistados & 490 & 497 & 500 \\
\hline
\end{tabular}

FONTE: NIEM-NUPESAL (2005). 
Os dados da Tabela 5 sugerem que um terço da população (dentro da margem de erro) nas três cidades estudadas considerou ser importante ter um líder forte para resolver os problemas do país, enquanto que, na média, mais de $65 \%$ dos entrevistados consideram que é a participação da população que pode potencializar a resolução dos problemas. Tais dados sinalizam que o tipo de cultura política existente nos contextos examinados é composto por uma mistura de desconfiança institucional elevada simultaneamente com um despertar crítico sobre a importância do papel da sociedade civil.

Como é conhecido, na teoria sobre cultura po- lítica, há uma diferença entre atitudes e comportamento. $\mathrm{O}$ fato de as pessoas mostrarem predisposições em relação a um determinado aspecto político não significa que, na realidade, elas participem. É fundamental que, na construção de uma cultura política democrática e participativa, os cidadãos mostrem uma consistência entre atitude e comportamento.

Nesse sentido, a participação popular, via associações informais ou grupos comunitários, ou seja, capital social, tem de mostrar um padrão significativo de crescimento. Este não parece ser o caso das cidades estudadas conforme os dados da Tabela 6.

TABELA 6 - ATUALMENTE O (A) SR. (A) PARTICIPA DE ALGUM GRUPO OU ORGANIZAÇÃO? (BRASIL, URUGUAI E CHILE)

\begin{tabular}{|lcccc|}
\hline & PORTO ALEGRE & MONTEVIDÉU & SANTIAGO DO CHILE \\
\hline Sim & 15,7 & 20,6 & 30,0 \\
Nẵo & 84,3 & 79,4 & 70,0 \\
Total de entrevistados & 490 & 497 & 500 \\
\hline
\end{tabular}

FONTE: NIEM-NUPESAL (2005).

De maneira geral, em relação ao percentual da participação em grupos ou organizações sociais ou comunitárias, Porto Alegre fica com o menor percentual de participação (15,7\%) e Montevidéu, com 20,6\%. Santiago fica com a maior participação (30\%). Chama a atenção o elevado percentual de pessoas que não participam de nenhum tipo de associação. Típico de sociedades latino-americanas, em que o Estado teve um papel preponderante historicamente, em que impera o "familismo", para usar uma expressão de Fukuyama (1996). Esses dados sinalizam que não podemos assumir automaticamente que o declínio da participação em atividades convencionais transforme-se, naturalmente, em participação comunitária. Os dados são eloqüentes de uma situação que nos parece grave, qual seja, um baixo padrão de participação dos cidadãos latino-americanos em qualquer tipo de atividade, seja ela política, comunitária ou social, muito embora os cidadãos de Montevidéu sejam mais propensos a participações "convenci- onais”, ao passo que os cidadãos de Santiago e Porto Alegre são mais propensos a participações “não convencionais” (BORBA, 2005) ${ }^{3}$. O caso latino-americano lembra a análise de Putnam (2000) sobre o Sul da Itália.

Para melhor compreender a relação, ou não, entre confiança interpessoal e democracia, foi feito um cruzamento entre estas duas variáveis. A tendência subjacente nos dados examinados anteriormente materializa-se quando essas variáveis são associadas.

3 Consideramos "participações convencionais" aquelas que acontecem dentro dos marcos institucionais da democracia, participação em partidos políticos, sindicatos, campanhas. As “não convencionais” realizam-se para além das instituições, ONGs, movimentos ambientalistas, protestos e boicotes a produtos de supermercados (TEORELL; TORÇAL \& MONTERO, 2003; NORRIS, 2004 apud AMORIM, 2005). 
TABELA 7 - CONFIANÇA INTERPESSOAL E SATISFAÇÃO COM A DEMOCRACIA (BRASIL, URUGUAI E CHILE)

\begin{tabular}{|c|c|c|c|c|c|c|}
\hline & \multicolumn{3}{|c|}{ PODE-SE CONFIAR NAS PESSOAS } & \multicolumn{3}{|c|}{ NÄO SE PODE CONFIAR NAS PESSOAS } \\
\hline & $\begin{array}{c}\text { PORTO } \\
\text { ALE GRE }\end{array}$ & MONTE VIEÉ U & $\begin{array}{l}\text { SANT LAGO } \\
\text { DO CHILE }\end{array}$ & $\begin{array}{c}\text { PORT O } \\
\text { ALE GRE }\end{array}$ & MONT EVIDE்U & $\begin{array}{l}\text { SANTIAGO } \\
\text { DO CHIILE }\end{array}$ \\
\hline $\begin{array}{l}\text { Satisfeito coma } \\
\text { democracia }\end{array}$ & 20,9 & 58,0 & 22,6 & 17,0 & 42,8 & 18,0 \\
\hline Pouco satisfeito & 51,3 & 32,4 & 39,1 & 42,4 & 36,9 & 39,0 \\
\hline $\begin{array}{l}\text { Insatisfeito com } \\
\text { a democracia }\end{array}$ & 27,8 & 8,0 & 34,8 & 40,6 & 17,4 & 39,0 \\
\hline $\begin{array}{l}\text { Total de } \\
\text { entrevisados }\end{array}$ & 481 & 500 & 487 & 481 & 500 & 487 \\
\hline
\end{tabular}

FONTE: NIEM-NUPESAL (2005).

NOTA: Porto Alegre: $\mathrm{N}=481 / \mathrm{X} 2=7,4082-\mathrm{P} .<0.05$; Montevidéu: $\mathrm{N}=500 / \mathrm{X} 2=27,80-\mathrm{P} .<0.05$; Santiago do Chile: $\mathrm{N}=487 / \mathrm{X} 2=$ $2,359-\mathrm{P} .>0.05)$

Observando a Tabela 7, constata-se que, de maneira geral, confiança interpessoal e satisfação com a democracia estão associados, 20,9\%, em Porto Alegre; 58\%, em Montevidéu; 22,6\%, em Santiago do Chile. Estes escores alteram-se quando a confiança cai. Então, temos uma diminuição da satisfação com a democracia, ficando $17 \%$, em Porto Alegre; 42,8\%, em Montevidéu; 18\%, em Santiago do Chile. Ou seja, quando diminui a confiança interpessoal nestas populações, diminui igualmente a satisfação com a democracia, tal qual os apontamentos sugeridos por Putnam (2000).

Aplicando-se o chi-square tests, nas três capitais analisadas, verificamos uma forte associação, entre confiança interpessoal e satisfação com a democracia, em, pelo menos, duas capitais. O que o teste demonstra é que há uma relação significativa entre as variáveis, tanto em Porto Alegre, quanto em Montevidéu. Todavia, no Chile, esta associação não se mostrou significativa.

Na seqüência de nossa análise, nos cruzamen- tos de confiança interpessoal com confiança nas instituições da democracia, como o Congresso Nacional, por exemplo, observarmos, na Tabela 8 , que a confiança nas pessoas está ligada à confiança no Congresso. Ou seja, quando diminui a confiança interpessoal nestas populações, diminui igualmente a confiança no funcionamento do Congresso. Tanto uruguaios quanto chilenos apresentaram uma tendência a confiar menos nesta instituição, à medida que a confiança nas pessoas também cai. Do total dos uruguaios que afirmaram confiar nas pessoas, 36,6\% afirmaram também confiar muito no Congresso Nacional de seu país; este percentual cai para $14,8 \%$ quando a confiança interpessoal decresce. No caso chileno, igualmente, há uma variação do percentual: de 7,3\% cai para 3,2\% quando a confiança diminui.

A exceção ficou com Porto Alegre, em que, do total das pessoas que disseram ter confiança interpessoal, 5,8\% afirmaram confiar muito no Congresso. Todavia, este percentual subiu para $6,9 \%$ quando a confiança diminuiu.

TABELA 8 - CONFIANÇA INTERPESSOAL E CONFIANÇA NO CONGRESSO NACIONAL. (BRASIL, URUGUAI E CHILE)

\begin{tabular}{|c|c|c|c|c|c|c|}
\hline & \multicolumn{3}{|c|}{ PODE-SE CONFIAR NAS PESSOAS } & \multicolumn{3}{|c|}{ NÄO SE PODE CONFIAR NAS PESSOAS } \\
\hline & \begin{tabular}{|c|} 
PORTO \\
ALEGRE
\end{tabular} & MONTE VIDÉU & $\begin{array}{l}\text { SANT LAGO } \\
\text { DO CHILE }\end{array}$ & $\begin{array}{c}\text { PORT O } \\
\text { ALEGRE }\end{array}$ & MONT EVIDÉU & $\begin{array}{l}\text { SANT LAGO } \\
\text { DO CHILE }\end{array}$ \\
\hline $\begin{array}{l}\text { Confia muito no } \\
\text { Congresso } \\
\text { Nacional }\end{array}$ & 5,8 & 36,6 & 7,3 & 6,9 & 14,8 & 3,2 \\
\hline $\begin{array}{l}\text { Confia pouco no } \\
\text { Congresso } \\
\text { Nacional }\end{array}$ & 65,4 & 46,6 & 68,7 & 45,3 & 53,0 & 49,9 \\
\hline $\begin{array}{l}\text { Nấo confia no } \\
\text { Congresso } \\
\text { Nacional }\end{array}$ & 28,8 & 13,9 & 22,6 & 47,8 & 29,2 & 45,0 \\
\hline $\begin{array}{l}\text { Nẫo sabe } \\
\text { Total de } \\
\text { entrevisados }\end{array}$ & $\begin{array}{l}0,0 \\
474\end{array}$ & $\begin{array}{l}2,9 \\
500\end{array}$ & $\begin{array}{l}0,9 \\
496\end{array}$ & $\begin{array}{l}0,0 \\
474\end{array}$ & $\begin{array}{l}3,0 \\
500\end{array}$ & $\begin{array}{l}1,9 \\
496\end{array}$ \\
\hline
\end{tabular}

\section{FONTE: NIEM-NUPESAL (2005).}

NOTA: Porto Alegre N=474/X2=17,405-P.<0.05; Montevidéu N=500/X2=43,100-P.<0.05; Santiago N=496/X2=22,403-P.<0.05. 
Aplicando-se o chi-square tests, verificamos uma associação significativa entre confiança interpessoal e confiança no Congresso Nacional nas três capitais analisadas, sugerindo que, pelo menos nas cidades estudadas neste trabalho, a correlação entre confiança interpessoal e confiança institucional é significativa.

Na Tabela 9, corroborando nosso argumento central, novamente confiança interpessoal interliga-se com as instituições da democracia. Aqui, confiança interpessoal e confiança no governo federal estão relacionadas. Ou seja, quando diminui a confiança interpessoal nestas populações, diminui igualmente a confiança no governo federal, como igualmente aconteceu em relação ao Congresso Nacional de Montevidéu e de Santiago. As três capitais analisadas apresentaram uma tendência a confiar menos na instituição governo federal, à medida que a confiança nas pessoas também cai. Do total dos brasileiros que afirmaram confiar nas pessoas, 15,5\% afirmaram também confiar muito no governo federal de seu país, mas este percentual cai para $8 \%$ quando a confiança interpessoal decresce. No caso uruguaio, novamente, do total de uruguaios que afirmaram confiar nas pessoas, 57,6\% também afirmaram confiar muito no governo. Este percentual cai para 31,4\% quando a confiança interpessoal decresce. Em Santiago do Chile, temos $24,6 \%$ e $14 \%$, respectivamente.

TABELA 9 - CONFIANÇA INTERPESSOAL E CONFIANÇA NO GOVERNO FEDERAL (PRESIDENTE E MINISTROS) (BRASIL, URUGUAI E CHILE)

\begin{tabular}{|c|c|c|c|c|c|c|}
\hline & \multicolumn{3}{|c|}{$\begin{array}{c}\text { PODE-SE CONFIAR NAS } \\
\text { PESSOAS }\end{array}$} & \multicolumn{3}{|c|}{$\begin{array}{l}\text { NÄO SE PODE CONFIAR NAS } \\
\text { PESSOAS }\end{array}$} \\
\hline & \begin{tabular}{|c|} 
PORT O \\
ALE GRE \\
\end{tabular} & $\begin{array}{l}\text { MONTE- } \\
\text { VDÉU }\end{array}$ & $\begin{array}{l}\text { SANT LAGO } \\
\text { DO CHILE }\end{array}$ & $\begin{array}{l}\text { PORTO } \\
\text { ALE GRE }\end{array}$ & $\begin{array}{l}\text { MONT E- } \\
\text { VDÉ U }\end{array}$ & $\begin{array}{l}\text { SANTIAGO } \\
\text { DO CHIILE }\end{array}$ \\
\hline Confia muito no governo & 15,5 & 57,6 & 24,6 & 8,0 & 31,4 & 14,0 \\
\hline Confia pouco no governo & 67,7 & 27,7 & 59,6 & 52,0 & 44,1 & 53,4 \\
\hline Nẫo confia & 14,9 & 12,2 & 15,8 & 38,8 & 22,9 & 32,3 \\
\hline Nẫo sabeinẫo respondeu & 2,5 & 2,1 & 0,0 & 1,2 & 1,7 & 0,3 \\
\hline Total de entrevistados & 481 & 500 & 495 & 481 & 500 & 495 \\
\hline
\end{tabular}

FONTE: NIEM-NUPESAL (2005)

NOTA: Porto Alegre: $N=481 / X 2=30,617-P .<0.05$; Montevidéu: $N=500 / X 2=43,963-P .<0.05$; Santiago do Chile: $N=495 /$ $X 2=15,330-P .<0.05$

Se a confiança interpessoal aparece relacionada com as instituições da democracia, como o Congresso, o governo, ela também aparece fortemente ligada à participação popular, em detrimento da confiança em líderes, ao estilo das "democracias delegativas” (O’DONNELL \& SCHMITTER,
1986). Se observarmos a Tabela 10 , veremos que, do total dos porto-alegrenses que disseram ter confiança interpessoal, 21,1\% concordaram com a afirmação de que "um líder seria necessário para resolver os problemas do país" e 75,8\% concordaram que "o melhor seria a participação popular".

TABELA 10 - CONFIANÇA NAS PESSOAS E O MELHOR PARA RESOLVER OS PROBLEMAS DO PAÍS (BRASIL, URUGUAI E CHILE)

\begin{tabular}{|l|c|c|c|c|c|c|}
\hline & \multicolumn{3}{|c|}{ PODE-SE CONF IAR } & \multicolumn{3}{c|}{ NÄO SE PODE CONF IAR } \\
\cline { 2 - 7 } & $\begin{array}{c}\text { PORT O } \\
\text { ALEGRE }\end{array}$ & $\begin{array}{c}\text { MONT E- } \\
\text { VIIÉ U }\end{array}$ & $\begin{array}{c}\text { SANT LAGO } \\
\text { DO CHILE }\end{array}$ & $\begin{array}{c}\text { PORTO } \\
\text { ALE GRE }\end{array}$ & $\begin{array}{c}\text { MONTE- } \\
\text { VIIÉ U }\end{array}$ & $\begin{array}{c}\text { SANTIAGO } \\
\text { DO CHIIE }\end{array}$ \\
\hline $\begin{array}{l}\text { Um líder que coloque as } \\
\text { coisas no lugar }\end{array}$ & 21,1 & 24,4 & 28,9 & 39,0 & 32,2 & 32,1 \\
$\begin{array}{l}\text { Participaçẫo popular nas } \\
\text { decisốes do gơvemo }\end{array}$ & 75,8 & 73,5 & 71,1 & 58,0 & 64,8 & 64,8 \\
Nẫo sabei nẫo respondeu & 3,1 & 2,1 & 0,0 & 3,1 & 2,9 & 3,0 \\
Total de entrevistados & 472 & 500 & 488 & 472 & 500 & 488 \\
\hline
\end{tabular}

FONTE: NIEM-NUPESAL (2005). 
Quando as pessoas não confiam umas nas outras, este percentual (a aposta no líder) sobe para 39\%. Em Montevidéu, repete-se o fenômeno, do total dos uruguaios da capital que disseram confiar nas pessoas, 24,4\% afirmaram que "um líder seria necessário para resolver os problemas do país" e 73,5\% concordaram que "o melhor seria a participação popular”. Quando cai a confiança, temos 32,2\% e 64,8\%, respectivamente. Em Santiago, o percentual teve uma variação de $28,9 \%$ e $71,1 \%$, caindo também em 32,1\% e 64,8\%. Ou seja, quanto menos confiança se tem nas pessoas, mais facilmente aposta-se em "saídas delegativas”, ao contrário, quando a confiança aumenta, igualmente aumenta o percentual de apostas na participação popular.

\section{CONSIDERAÇÕES FINAIS}

Este artigo procurou demonstrar, por meio de evidências empíricas em três capitais investigadas na América Latina: Porto Alegre, Montevidéu e Santiago do Chile, a hipótese clássica de Putnam (2000) de que existe uma forte associação entre capital social e democracia. Parece-nos que os dados aqui examinados são importantes ao desvendarem que a existência de estoques de capital social (operacionalizado em termos de confiança interpessoal e institucional), em uma determinada sociedade, influencia positivamente a crença no regime democrático e em suas instituições.

Algumas inquietações que serão examinadas em futuros trabalhos dizem respeito à relação entre participação social e comunitária e suas relações com o capital social. No entanto, alguns caminhos podem ser apontados. Primeiro: os dados revelam que a confiança interpessoal que estabelece-se em determinada configuração societal está diretamente relacionada à crença que estas populações nutrem por suas instituições. Segundo: nas três capitais analisadas, este fenômeno repete-se, muito embora apresentando algumas variações. Condições societais que favorecem o capital social levam ao apoio dessas populações às instituições democráticas e vice-versa.

Nos casos de Porto Alegre e Santiago do Chile, chama atenção o fato de que estas capitais apresentem os escores mais baixos tanto de confiança interpessoal quanto de satisfação com a democracia. Pode-se constatar este fato por meio da análise das freqüências e aplicações de chi-square tests. Como podemos explicar este fenômeno?
Em uma primeira aproximação, poderíamos apontar o fato da longa duração dos regimes militares instituídos nestas duas sociedades e que foram responsáveis, entre outras conseqüências, pelo dilaceramento institucional político das instituições democráticas, acabando, por exemplo, com tradições partidárias significativas e importantes que vinham sendo gestadas anteriormente às respectivas rupturas institucionais. No Chile, com a deposição do Presidente Allende, em 1973, ou mesmo no Brasil, com a deposição de Jango, com o fim do pluralismo partidário, em 1964, e a instauração do bipartidarismo Movimento Democrático Brasileiro (MDB) e Aliança Renovadora Nacional (Arena). No caso brasileiro, tivemos juntamente da instauração do regime autoritário também um reforçamento da intervenção do Estado na economia, aplicando-se uma política econômica que levou o país a ter altas taxas de crescimento econômico, o chamado "milagre econômico". Isto talvez explique o fato de que a democracia não esteja associada ao crescimento econômico ou ao bem-estar social, ao contrário, foi justamente nos anos do regime autoritário que tivemos as maiores taxas de crescimento, ao passo que, na década transicional dos anos 1980, ocorreu uma "década perdida”. A cultura política local associa freqüentemente autoritarismo com desenvolvimento. Todavia, chama a atenção, no caso de Porto Alegre, em que vigora por quase duas décadas o chamado OP (Orçamento Participativo), em que os baixos escores de participação e confiança interpessoal destas populações permanece. Do esperado eleitor cívico parece ter sobrado um eleitor mais “pragmático" (BAQUERO, 1997; BORBA, 2005). Também os dados de Porto Alegre devem ser compreendidos à luz do impacto das denúncias de corrupção, envolvendo diretamente o Congresso Nacional brasileiro no ano de 2005. Este aspecto conjuntural certamente influenciou os escores baixos de confiança no Congresso Nacional, uma das instituições mais afetadas com os escândalos no corrente ano.

Em Santiago do Chile, a instauração do regime autoritário parece ter tido implicações mais graves tanto nos planos político quanto econômico, principalmente no que diz respeito à implantação pioneira das chamadas "políticas neoliberais" dos "Chicago boys" a partir dos anos 1970, que acabaram fomentando uma sociedade despolitizada, desmobilizada que incentiva o "personalismo" da “competência técni- 
ca” na gestão da coisa pública (BORBA, 2005).

Montevidéu foi a capital que surpreendeu, justamente pelo fato de apresentar níveis de confiança interpessoal e satisfação com a democracia acima dos casos de Porto Alegre e Santiago do Chile. Este também foi um país que enfrentou um regime autoritário, a partir de 1973, permanecendo até os anos 1980. Todavia, suas trajetórias histórica e política permitiram a configuração de uma "cultura política participante”, segundo a bibliografia especializada. Borba (2005), ao elaborar uma revisão da literatura pertinente à cultura política do Uruguai, elenca vários fatores que poderiam explicar os índices mais altos de confiança interpessoal e apoio à democracia. Por exemplo, a permanência de tradições partidárias que remontam o século XIX, a forte influência do liberalismo político somado à forte intervenção estatal, a atuação dos meios de comunicação na formação de consensos sobre as decisões políticas mais importantes no período da transição do autoritarismo, a democracia no Uruguai, bem como a experiência do governo da "Frente Ampla” em Montevidéu, que permitiu que os uruguaios vivenciassem experiências de participação pública direta neste país.

Os resultados deste artigo sugerem que a teoria de capital social pode se constituir num elemento importante à teoria da democratização, sobretudo, se pensada em termos de redução da pobreza e o estabelecimento de bases socialmente eqüitativas. No entanto, é necessário ter cautela na análise deste conceito em sociedades materialmente não resolvidas e pressupor que capital social já existe.
Nossa pesquisa mostra que os estoques de capital social nas cidades estudadas são baixos e seu impacto, embora importante como dispositivo alternativo de expressar demandas e reivindicações e solução de problemas locais, está longe de ser um elemento permanentemente presente no processo de construção democrática dos nossos países.

Se este artigo, a partir da análise dos dados da pesquisa comparativa, corrobora a hipótese de que há uma associação significativa entre capital social e democracia e que esta associação manifesta-se de forma diferente nos países estudados, constitui-se num desafio refletir a respeito das possibilidades apresentadas nessas configurações societais para explicarmos a criação de capital social, como também nos obstáculos postos à sua construção 4 . A realidade é que, a despeito da influência positiva que o capital social pode ter no fortalecimento democrático, como foi argumentado, o estoque deste tipo de capital é mínimo e está em processo de esfriamento. A tarefa imediata parece-nos ser o desenvolvimento de esforços de constituição de capital social na América Latina.

\footnotetext{
4 Em relação à criação de capital social, muito embora não esteja nos objetivos deste trabalho sua discussão, é importante sublinhar que há um debate bastante importante sobre as possibilidades de o Estado, por meio de políticas públicas, estimulá-lo. Entretanto, este Estado pode também constituir-se em obstáculo para a criação de capital social, à medida que estabelece, a partir de relações verticais de clientelismo e patrimonialismo, dificuldade de consolidação de relações horizontais de cooperação e confiança.
}

Everton Santos (evertons@feevale.br) é Doutor em Ciência Política pela Universidade Federal do Rio Grande do Sul (UFRGS), Professor permanente do Programa de Pós-Graduação em Inclusão Social e Acessibilidade do Centro Universitário Feevale (Feevale) e Professor colaborador no Programa de PósGraduação em Odontologia da Universidade Luterana do Brasil (Ulbra).

Marcello Baquero (baquero@cresce.net) é Doutor em Ciência Política pela Florida State University (EUA) e Professor do Programa de Pós-Graduação em Ciência Política da Universidade Federal do Rio Grande do Sul (UFRGS).

\section{REFERÊNCIAS BIBLIOGRÁFICAS}

ALMOND, G. \& VERBA, S. 1989. The Civic Culture : Political Attitudes and Democracy in Five Nations. Newbury Park : Sage.

AMORIM, M. S. S. 2005. Desenvolvimento sustentável na perspectiva da cultura política e da participação democrática. Debates, Porto Alegre, p. 85-99.

BAQUERO, M. 1997. Novos padrões de comportamento eleitoral : pragmatismo nas eleições municipais de 1996 em Porto Alegre. In : 
. (org.). A lógica do processo eleitoral em tempos modernos - novas perspectivas de análise. Porto Alegre : UFRGS.

1999. Partidos e cultura política na América Latina : uma combinação de instabilidade política? In : . (org.). Desafios da democratização na América Latina : debates sobre cultura política. Porto Alegre : UFRGS.

. 2005. Sem confiança a democracia se torna inerte : é o capital social uma resposta? Um estudo sobre a América Latina. Educação Unisinos, São Leopoldo, v. 9, n. 2, p. 84-98.

BORBA, J. 2005. Comportamento político e capital social na América Latina. Debates, Porto Alegre, p. 55-68.

BOURDIEU, P. 1980. Le capital social : notes provisoires. Actes de la Recherche en Sciences Sociales, Paris, v. 31, p. 2-3.

CAROTHERS, T. 2002. The End of the Transition Paradigm. Journal of Democracy, v. 13, p. 1.

COLEMAN, J. S. 1988. Social Capital in the Creation of Human Capital. American Journal of Sociology, v. 94, p. S95-S120. Supplement.

DAHL, R. 1997. Poliarquia : participação e oposição. São Paulo : USP.

FUKUYAMA, F. 1996. Confiança : as virtudes sociais e a criação da prosperidade. Rio de Janeiro : Rocco.

HUNTINGTON, S. 1994. A terceira onda : democratização no final do século XX. São Paulo : Ática.

INGLEHART, R. 1978. The Silent Revolution. Princeton : Princeton University.
LAMOUNIER, B. 1987. Perspectivas da consolidação democrática : o caso brasileiro. Revista Brasileira de Ciências Sociais, São Paulo, v. 2, n. 4, p. 44.

MAINWARING，S. 1992. Transitions to Democracy and Democratic Consolidation : Theoretical and Comparative Issues. In : MAINWARING, S.; O'DONNELL, G. \& VALENZUELA, A. (eds.). Issues in Democratic Consolidation : the New South American Democracies in Comparative Perspective. Notre Dame : University of Notre Dame.

MOISÉS, J. A. 1995. Os brasileiros e a democracia : bases sócio-políticas da legitimidade democrática. São Paulo : Ática.

NIEM-NUPESAL. 2005. Desenvolvimento sustentável e capital social na promoção da cidadania e qualidade de vida na América Latina. Relatório de pesquisa. Porto Alegre: Núcleo de Estudos sobre a Mulher e Gênero-Núcleo de Estudos sobre a América Latina UFRGS.

NUN, J. 1994. La democracia y la modernización : treinta años después. In : SIERRA, G. (org.). Democracia emergente en América del Sur. Ciudad de México : UNAM.

O'DONNELL, G. \& SCHMITTER, P. C. 1986. Autoritarismo e democratização. São Paulo : Vértice.

1988. Transições do regime autoritário. São Paulo : Vértice.

PUTNAM, R. 2000. Comunidade e democracia : a experiência da Itália moderna. Rio de Janeiro : Fundação Getúlio Vargas. 
DEMOCRACY AND SOCIAL CAPITAL IN LATIN AMERICA: A COMPARATIVE ANALYSIS

Everton Santos e Marcello Baquero

The main purpose of this article is to identify societal conditions that may work to favor democracy in Latin América, articulating this concept of democracy with the concept of social capital, as outlined by Putnam (2000). Our working hypothesis posits a significant association between social capital and democracy. We also believe that the existence of stocks of social capital, within a particular society, is a positive influence on belief in democratic regimes and their institutions. Our hypothesis uses data from three South American capitals: Porto Alegre (Brazil), Montevideo (Uruguay) and Santiago de Chile (Chile), gathered in three research projects that were applied in these countries. KEYWORDS: democracy; social capital; Latin América. 
DÉMOCRATIE ET CAPITAL SOCIAL EN AMÉRIQUE LATINE: UNE ANALYSE COMPARATIVE

\section{Everton Santos e Marcello Baquero}

Cet article a pour objectif l'identification de possibles conditions sociétales favorisant la démocratie en Amérique latine, et articule ainsi le concept de démocratie et le concept de capital social dans la tradition de Putnam (2000). Notre hypothèse est celle de l'existance d'une association importante entre capital social et démocratie. Nous croyons aussi que l'existance de stocks de capital social, dans une société, influe positivement la croyance en un régime démocratique et ses institutions. L'hypothèse utilise les données de trois capitales sud-américaines : Porto Alegre (Brésil), Montévidéo (Uruguay) et Santiago (Chili), à partir de trois recherches appliquées dans ces pays.

MOTS-CLÉS: démocratie; capital social; Amérique Latine. 